\title{
ВЛИЯНИЕ УЛЬТРАЗВУКОВОЙ КАВИТАЦИОННОЙ ДИСПЕРГАЦИИ НА ФРАКЦИОННЫЙ СОСТАВ И СОРБЦИОННЫЕ СВОЙСТВА ТОРФА ПО ОТНОШЕНИЮ К ИОНАМ Cu (II)
}

\author{
() Е.Ф. Лозинская ${ }^{I}$ Н.И. Косолапова ${ }^{I}$, А.В. Смородько ${ }^{2}$, Т.Н. Митракова ${ }^{1 *}$ \\ ${ }^{1}$ Курский государственный университет, ул. Радищева, 33, Курск, 305000 \\ (Россия), e-mail: t-mitrakova@rambler.ru \\ ${ }^{2}$ ООО «Торгово-производственная компания «Кавита», ул. Б. Галушкина, 23, \\ Москва, 129301 (Россия), e-mail:Torf-info@yandex.ru
}

Ультразвуковая кавитационная диспергация торфа до заданных наноразмеров при высоком статическом давлении позволяет получить продукт, обладающий ценными потребительскими качествами. При определении фракционногруппового состава органического вещества торфа, подвергшегося диспергации и исходного образца по методу Н.Н. Бамбалова, Т.Я. Беленькой, показано, что в результате диспергации снижается содержание битумоидов в 2,1 раза, трудногидролизуемых (целлюлоза) и негидролизуемых (лигнин) веществ - в 2,0 и 1,3 раза соответственно, наблюдается увеличение содержания гуминовых кислот, извлекаемых и 0,1 М раствором щелочи (в 1,6 раза) и 0,025 М раствором пирофосфата натрия (в 5,9 раза), увеличивается массовая доля суммы водорастворимых и легкогидролизуемых веществ (в 1,4 раза) по отношению к исходному торфу.

Также наблюдается улучшение сорбционных свойств по отношению к ионам меди (II). Для образцов торфа с разной степенью диспергирования максимальная степень сорбции ионов меди (II) достигается при рН 4,6 и поддерживается практически без изменения до 7,2, максимум сорбции на исходном торфе приходится на интервал рН 6,26,4. Изотермы сорбции относятся к L-типу. B результате ультразвуковой кавитационной обработки сорбционная емкость торфа увеличивается в 2,1 раза. Лучшими сорбционными свойствами обладает образец торфа, подвергшейся обработке в течение 10 мин (COE=1,65 ммоль/г).

Изучение кинетических зависимостей показали, что процесс сорбции на изучаемых сорбентах протекает достаточно быстро и практически заканчивается через 7 мин. Ультразвуковая кавитационная диспергация торфа приводит к увеличению константы скорости сорбции.

Показана возможность использования диспергированного торфа в качестве сорбента для доочистки сточных вод от ионов меди (II) гальванопроизводств, прошедших через доломитовый фильтр. Установлено, что для торфа, подвергшегося ультразвуковой кавитационной обработке в течение 10 мин, характерна более высокая степень извлечения. Содержание меди после сорбции снижается в 9,49 раза, остаточная концентрация составляет 0,01-0,03 мг/дм³.

Ключевые слова: торф, ультразвуковая диспергация, сорбция, ионы меди, сточные воды.

\section{Введение}

Очистка медьсодержащих стоков, образующихся в технологических процессах гальванических производств, является серьезной проблемой для экологических служб предприятий. Для катионов меди нормативы сброса в городскую канализацию значительно ниже, чем предельно-допустимая концентрация ионов $\mathrm{Cu}^{2+}$ в питьевой воде, поэтому поиск новых и усовершенствование существующих методов очистки продолжает оставаться актуальным направлением исследований [1].

\footnotetext{
Лозинская Елена Фёдоровна - доцент кафедры химии Курского государственного университета, кандидат химических наук, тел. (4712)56-73-10, e-mail: lozinskaya.ed@mail.ru Косолапова Наталья Игоревна - доцент кафедры химии Курского государственного университета, кандидат химических наук, тел. (4712)56-73-10, e-mail: Nataliko7@yandex.ru
}

Продолжение на с. 210.
Одним из эффективных методов очистки сточных вод от ионов металлов является сорбционный метод, позволяющий проводить доочистку до низких концентраций загрязнителя и повторно использовать очищенную воду в замкнутых системах водооборота предприятий. Эффективность сорбционной очистки в зависимости от применяе-

\footnotetext{
* Автор, с которым следует вести переписку.
} 
мого сорбента составляет 80-95\% [2]. В качестве сорбентов используют активированный уголь, угольные волокна, синтетические сорбенты, силикагели, гидраты оксидов металлов. Для очистки от катионов металлов все большее применение находят сорбенты природного происхождения (меловые и глинистые породы, цеолиты, песок), которые отличаются дешевизной и доступностью [3]. Одним из важнейших природных сорбентов является торф. Сорбционные свойства торфа связаны с присутствием в его структуре таких функциональных групп, как аминные, амидные, спиртовые, альдегидные, карбоксильные, карбоксилатные, кетонные, фенольные, хинонные и метоксильные. Все они находятся, прежде всего, в структуре полимолекулярных ассоциатов: гуминовых веществ (в основном гуминовых и фульвокислот), лигнина [4]. К тому же свойства торфа можно значительно изменить путем химического или физического воздействия. Одним из методов улучшения сорбционных характеристик торфа за счет увеличения его удельной поверхности является ультразвуковая кавитационная диспергация в водной среде при высоком статическом давлении. Данный способ обработки представляет собой следующую последовательность операций:

- загрузка торфа в воздушно-сухом состоянии в смеси с заданным объемом воды в диспергационную камеру так, чтобы массовое соотношение торф - вода составляло от $1: 1,5$ до $1: 3,5$;

- герметизация диспергационной камеры;

- подача в герметизированную диспергационную камеру при помощи насоса заранее заданного статического давления порядка 507-709 кПа;

- обработка содержимого диспергационной камеры ультразвуковыми колебаниями с плотностью озвучивания не менее $50 \mathrm{BT} / \mathrm{cm}^{2}$, обеспечивающими в течение заранее заданного времени звуковое давление на смесь торфа с водой, превышающее статическое давление на заранее заданную величину. Источником ультразвука может быть как известный специалистам магнитострикционный преобразователь, расположенный, например, под днищем камеры, так и магнитоакустический генератор, в котором цилиндрическая стенка камеры вибрирует под действием наводимых в ней вихревых токов.

Такая обработка вызывает образование в торфо-водяной смеси кавитационных пузырьков с их последующим схлопыванием. Известно, что схлопывающийся кавитационный пузырек способен диспергировать твердые частицы, размеры которых больше его собственной критической величины. За счет соответствующего выбора параметров указанный способ диспергирования обеспечивает измельчение торфяных частиц до величин порядка 40-60 нм. В результате обработки получается черно-коричневая пастообразная масса, обладающая выраженными сорбционными свойствами по отношению к d-металлам.

Цель настоящей работы - изучение влияния ультразвуковой кавитационной диспергации на фракционный состав торфа, изменений его сорбционных свойств по отношению к ионам $\mathrm{Cu}^{2+}$ в зависимости от продолжительности обработки и оценка возможности использования диспергированного торфа в качестве сорбента ионов меди (II) для очистки гальванических стоков.

\section{Экспериментальная часть}

Ценность торфа определяется составом и свойствами его органической части. Для определения фракционно-группового состава органического вещества исходного образца торфа и торфа, подвергшегося диспергации, был выбран метод Н.Н. Бамбалова, Т.Я. Беленькой [5]. Схема анализа представлена на рисунке 1. Диспергированный торф перед проведением экстракции битумоидов был высушен до состояния естественной влажности (48\%) при температуре $50{ }^{\circ} \mathrm{C}$.

Изучение сорбционных свойств по отношению к $\mathrm{Cu}^{2+}$ проводили для образца торфа, не подвергшегося обработке (образец 5), а также для 4 образцов, подвергшихся ультразвуковой кавитационной диспергации [6] при высоком давлении продолжительностью от 3 до 15 мин в водной среде (образцы 1-4). Поскольку необработанный образец торфа отличался от других содержанием воды, произвели гидратацию сухого торфа до влажности обработанных образцов (образец 6). Характеристики исследуемых сорбентов приведены в таблице 1.

Концентрация ионов меди в исходном растворе составляла 1 г/дм³. Растворы меньшей концентрации

Смородько Александр Владимирович - директор по науке и развитию новых технологий ООО «Торговопроизводственная компания «КАВИТА», доктор физикоматематических наук, тел. (495)226-18-22,

e-mail: Torf-info@yandex.ru Митракова Татьяна Николаевна* - аспирант кафедры химии Курского государственного университета, тел. (4712)56-73-10, e-mail; t-mitrakova@ rambler.ru получали разбавлением исходного раствора. Необходимое значение $\mathrm{pH}$ растворов устанавливали добавлением растворов соляной кислоты, гидроксида натрия (0,1 моль/дм $\left.{ }^{3}\right)$, ацетатных буферных растворов. Значения $\mathrm{pH}$ растворов контролировали потенциометрически с применением иономера И-130 с точностью $\pm 0,05$. 
Рис. 1. Схема анализа фракционногруппового состава органического вещества торфов по методу

Н.Н. Бамбалова, Т.Я. Беленькой, где Б - битумы, ГВ - гуминовые вещества, ГК - гуминовые кислоты, ФК - фульвокислоты, ВР - водорастворимые вещества, ЛГ - легкогидролизуемые вещества, ТГ - трудногидролизуемые вещества (целлюлоза), НО - негидролизуемый остаток (лигнин)

Изучение сорбции в статических условиях проводили при соотношении сорбент : модельный раствор = $1: 1000$ в диапазоне концентраций ионов меди (II) от $1,57 \cdot 10^{-3}$ ммоль/дм ${ }^{3}$ до 1,57 ммоль/дм ${ }^{3}$. Экспозиция фазы сорбента в растворе составляла 24 ч. Содержание ионов меди в растворах до и после сорбции определяли экстракционно-фотометрически с диэтилдитиокарбаматом свинца [7]. Для контроля оптической плотности использовали спектрофотометр UV-1800 Shimadzu.

Оценку возможности применения образцов для сорбционной доочистки сточных вод проводили с использованием реальных объектов (гальванических стоков, прошедших через доломитовый фильтр, с различным содержанием ионов меди (II)) в статических условиях методом постоянного объема раствора и перемен-

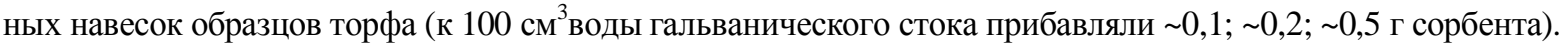

\section{Обсуждение результатов}

Результаты изучения фракционно-группового состава органического вещества исходного и диспергированного торфа представлены в таблице 2.

Показано, что в образце диспергированного торфа по сравнению с исходным образцом снижено содержание битумоидов в 2,1 раза, трудногидролизуемых (целлюлоза) и негидролизуемых (лигнин) веществ - в 2,0 и 1,3 раза соответственно. Наблюдается увеличение содержания гуминовых кислот, извлекаемых как 0,1 М раствором щелочи (в 1,6 раза), так и 0,025 М раствором пирофосфата натрия (в 5,9 раза), а также массовой доли суммы водорастворимых и легкогидролизуемых веществ (в 1,4 раза). 
Таблица 2. Фракционно-групповой состав органического вещества (\%)* исходного и диспергированного торфа

\begin{tabular}{|c|c|c|c|c|}
\hline \multirow{3}{*}{\multicolumn{3}{|c|}{ Фракционно-групповой состав }} & \multicolumn{2}{|c|}{$\mathrm{x} \pm \Delta \mathrm{x}, P=0,95, n=3$} \\
\hline & & & \multicolumn{2}{|c|}{ торф } \\
\hline & & & исходный & диспергированный \\
\hline Общее соде & ние органическог & $\mathrm{a}(\mathrm{OB})$ & $91,2 \pm 2,5$ & $91,5 \pm 2,2$ \\
\hline \multirow{6}{*}{$\begin{array}{l}\text { Массовая доля } \\
\text { ОВ во фракции }\end{array}$} & \multicolumn{2}{|c|}{ Б } & $13,7 \pm 0,5$ & $6,5 \pm 0,8$ \\
\hline & щелочной & $\begin{array}{c}\text { ГК-1 } \\
\Phi К\end{array}$ & $\begin{array}{c}23,4 \pm 0,9 \\
5,6 \pm 0,3\end{array}$ & $\begin{array}{c}36,3 \pm 1,1 \\
3,5 \pm 0,2\end{array}$ \\
\hline & пирофосфатной & $\Gamma \mathrm{\Gamma}-2$ & $2,1 \pm 0,2$ & $12,5 \pm 0,5$ \\
\hline & \multicolumn{2}{|c|}{ ВР и ЛГ } & $14,9 \pm 1,3$ & $20,7 \pm 1,5$ \\
\hline & \multicolumn{2}{|c|}{$\mathrm{T} \Gamma$} & $8,0 \pm 0,6$ & $4,1 \pm 0,3$ \\
\hline & \multicolumn{2}{|c|}{$\mathrm{HO}$} & $25,6 \pm 0,4$ & $20,4 \pm 0,5$ \\
\hline
\end{tabular}

* Расчет массовых долей ОВ каждой фракции произведен на абсолютно-сухое вещество образцов.

Зависимость степени сорбции от рН исследовали в диапазоне рН от 1 до 8,2; начальная концентра-

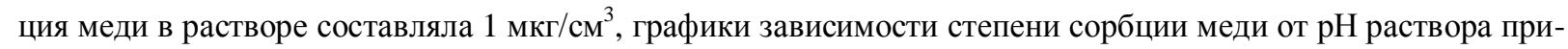
ведены на рисунке 2. Степень сорбции ионов меди при установленных значениях рН находили (1):

$$
R=\frac{C_{0}-C}{C_{0}} \cdot 100 \%,
$$

где $C_{0}$ - исходная концентрация $\mathrm{Cu}^{2+}$ в растворе, мг/дм ${ }^{3} ; C$ - равновесная концентрация $\mathrm{Cu}^{2+}$ в жидкой фазе после сорбции, мг/дм ${ }^{3} ; R$ - степень сорбции, \%.

Исследуемый исходный торф имеет довольно узкий диапазон рН максимальной сорбции 6,2-6,4. Для образцов торфа с различной степенью диспергирования максимальная степень извлечения меди достигается уже при рН 4,6 и поддерживается практически без изменения до 7,2. При более высоких значениях $\mathrm{pH}(>7,5)$ степень извлечения меди из раствора незначительно падает.

Механизм сорбции катионов тяжелых металлов обусловлен протолитическими формами в растворе сорбата и сорбента в диапазоне рН максимальной сорбции [8]. Опираясь на константы устойчивости аквагидроксо- и гидроксокомплексов $\mathrm{Cu}(\mathrm{II})\left(\lg \beta_{1}=6,65 ; \lg \beta_{2}=13,68 ; \lg \beta_{3}=15,0 ; \lg \beta_{3}=15,89\right)$ и константу растворимости гидроксида меди (II) $\left(\mathrm{K}_{\mathrm{s}}=5,6 \cdot 10^{-20}\right)$, можно сказать, что в диапазоне рН меньше 6 преобладающей протолитической формой является $\left[\mathrm{Cu}\left(\mathrm{H}_{2} \mathrm{O}\right)_{4}\right]^{2+}(\alpha=0,905)$, при рН 7 валовая концентрация протолитических форм меди (II) в растворе составляет $1,4 \cdot 10^{-5}$ моль/дм ${ }^{3}$. Для торфяных гуминовых кислот показано [9], что в диапазоне рН от 3 до 8 депротонируются карбоксильные группы: более сильные - от 3 до 4, более слабые - от 6,2 до 6,5. Детоксикационные свойства торфа по отношению к ионам тяжелых металлов, как правило, связывают с комплексообразованием карбоксильных групп гуминовых и фульвокислот [10]. Поскольку в результате ультразвуковой кавитационной обработки увеличивается доступность карбоксильных групп торфяных кислот, что проявляется в увеличении содержания извлекаемых гуминовых и фульвокислот, то вероятным механизмом сорбции ионов меди (II) можно считать комплексообразование с участием карбоксиланионных форм. Вероятно, при диспергации увеличивается содержание сильнокислотных карбоксильных групп, поэтому диапазон рН в котором степень сорбции максимальна, расширяется.

Таким образом, в диапазоне $\mathrm{pH}$ от 4,6 до 6,4 из раствора извлекается гидратированный ион $\mathrm{Cu}^{2+}$ в результате комплексообразования, при дальнейшем увеличении $\mathrm{pH}$ раствора некоторый вклад вносит осаждение, нельзя исключить также процессы физической адсорбции катиона, ионного обмена и других.

При оптимальных значениях кислотности среды (рH $\sim 6)$ и температуре $25 \pm 2{ }^{\circ} \mathrm{C}$ построены изотермы сорбции (кривые зависимости равновесной концентрации меди в растворе $\left(\mathrm{C}\right.$, ммоль/дм $\left.{ }^{3}\right)$ от удельной концентрации меди в твердой фазе сорбента (А, ммоль/г) (рис. 3).

Построенные изотермы однообразны и относятся к L-типу [11]. При низких концентрациях ионы меди (II) имеют относительно высокое сродство с сорбентом. По мере заполнения сорбционных центров уменьшается количество незаполненных сорбционных позиций и, соответственно, снижается количество сорбированного элемента. 


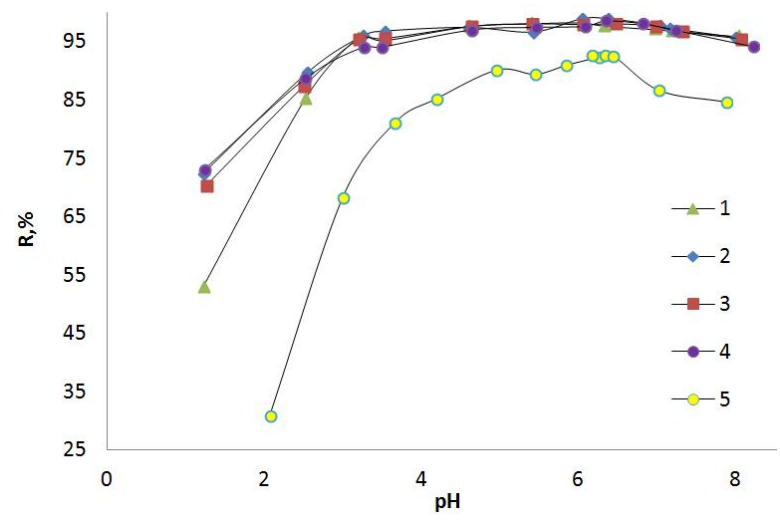

Рис. 2. Зависимость степени сорбции ионов меди (II) от $\mathrm{pH}$ среды для образцов 1-5

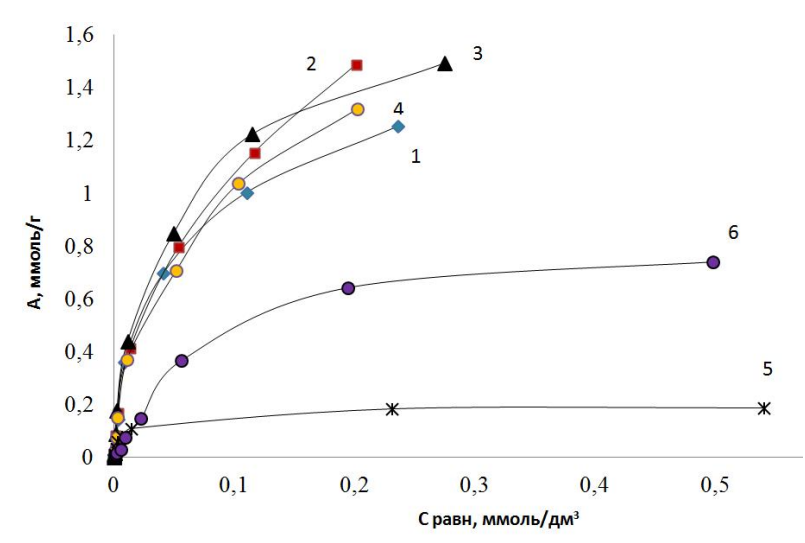

Рис. 3. Изотермы сорбции ионов меди (II) для образцов торфа 1-6( $\mathrm{pH} \sim 6)$

Экспериментальные данные были аппроксимированы с помощью наиболее часто используемых для этих целей уравнений - уравнений Генри (2), Ленгмюра (3), Фрейндлиха (4):

$$
A=K_{\Gamma} \cdot \mathrm{C}
$$

где $A$ - удельная адсорбция, ммоль/г; $K_{\text {г }}$ - константа Генри; $C$ - равновесная концентрация $\mathrm{Cu}^{2+}$ в растворе, ммоль/дм ${ }^{3}$.

$$
A=A_{\text {пр }} \cdot \frac{K_{L} \cdot C}{1+K_{L} \cdot C},
$$

где $A$ - удельная адсорбция, ммоль/г; $A_{n p}$ и $K_{L}$ - константы Ленгмюра, связанные с эффективностью адсорбции и энергией адсорбции соответственно; $C$ - равновесная концентрация $\mathrm{Cu}^{2+}$ в $р$ астворе, ммоль/дм ${ }^{3}$.

$$
A=K_{\mathrm{F}} \cdot \mathrm{C}^{1 / \mathrm{n}}
$$

где $A$ - удельная адсорбция, ммоль/г; $K_{F}$ - константа Фрейндлиха, $1 / n-$ показатель степени, варьирующий в интервале от 0 до 1, который можно рассматривать как показатель неоднородности сорбционных центров (величина $1 / n$ приближается к 0 по мере возрастания неоднородности и стремится к 1 при увеличении их однородности [12]); $C$ - равновесная концентрация элемента в растворе, ммоль/дм³

Удельная адсорбция пропорциональна равновесному содержанию ионов $\mathrm{Cu}^{2+}$ в растворе в диапазоне концентраций от $1,57 \cdot 10^{-3}$ до $7,87 \cdot 10^{-2}$ ммоль/дм ${ }^{3}$ (участки Генри изотерм). Модель Ленгмюра удовлетворительно описывает участки изотерм в диапазоне концентраций ионов меди (II) от $3,15 \cdot 10^{-2}$ до 1,57 ммоль/дм ${ }^{3}$, а модель Фрейндлиха - в диапазоне от 6,29.10-3 до 1,57 ммоль/дм³.

В таблице 3 приведены основные параметры сорбции ионов меди (II) исследуемыми образцами.

Данные, приведенные в таблице 3, свидетельствуют о том, что метод ультразвуковой кавитации приводит к увеличению сорбционной емкости торфа по отношению к ионам меди (II) более чем в 2 раза. Лучшими сорбционными свойствами обладает образец 3 ( $\mathrm{COE}=1,65$ ммоль/г, превышает сорбционную емкость исходного торфа в 2,1 раза). Наибольшей энергией адсорбции обладает исходный негидратированный торф (образец 5) ( $K_{L}$ максимальна), что можно объяснить за счет дополнительного выделения энергии при гидратации. С увеличением продолжительности ультразвуковой кавитационной диспергации до 15 мин происходит некоторое снижение сорбционной емкости торфа по ионам $\mathrm{Cu}^{2+}$. Это может быть связано с увеличением неоднородности сорбционных центров ( $1 / n$ падает) при одновременном снижении их

\begin{tabular}{|c|c|c|c|c|c|}
\hline Номер образца & $\mathrm{K}_{\Gamma,}, \mathrm{M}^{3} / \Gamma$ & $\mathrm{K}_{\mathrm{L},}$ Дм $\mathrm{M}^{3} / \Gamma$ & $\mathrm{A}_{\text {пр, }}$, ммоль/Г & $K_{\mathrm{F}}$ & $1 / \mathrm{n}$ \\
\hline 1 & 33,17 & 32,62 & 1,41 & 4,18 & 0,58 \\
\hline 2 & 35,38 & 32,72 & 1,27 & 4,48 & 0,65 \\
\hline 3 & 44,35 & 29,56 & 1,65 & 7,72 & 0,78 \\
\hline 4 & 54,39 & 24,07 & 1,53 & 6,77 & 0,74 \\
\hline 5 & 20,21 & 112,98 & 0,19 & 4,19 & 0,22 \\
\hline 6 & 7,50 & 12,07 & 0,78 & 3,60 & 0,91 \\
\hline
\end{tabular}
количества за счет процессов агрегации, происходящих между мелкодисперсными частицами торфа.

Таблица 3. Основные параметры сорбции ионов меди (II) исследуемыми образцами 1-6 
Кинетические исследования показали, что процесс сорбции на изучаемых сорбентах протекает достаточно быстро и практически заканчивается через 7 мин при массовом соотношении раствор : сорбент = 1000 : 1. На рисунке 4 представлены интегральные кинетические кривые сорбции ионов меди (II) на гидратированном (образец 6) и диспергированном торфах (образец 3).

Для описания сорбционного процесса использовали модели псевдо-первого и псевдо-второго порядка [13]. Линейные формы этих моделей представлены уравнениями (5) и (6) соответственно.

$$
\begin{gathered}
\ln \left(A_{e}-A_{t}\right)=\ln A_{e}-k_{1} \cdot t, \\
\frac{t}{A_{t}}=\frac{1}{k_{2} \cdot A_{e}^{2}}+\frac{1}{A_{e}} \cdot t,
\end{gathered}
$$

где $A_{e}$ и $A_{t}-$ количество сорбированного иона металла на единицу массы сорбента в состоянии равновесия и в момент времени $\mathrm{t}$, ммоль/г; $\mathrm{k}_{1}$ - константа скорости сорбции модели псевдо-первого порядка, мин ${ }^{-1}$; $\mathrm{k}_{2}$ - константа скорости сорбции модели псевдо-второго порядка, г/ммоль ммин.

На рисунке 5 представлены анаморфозы кинетических кривых в модели псевдо-первого порядка (зависимость $\ln \left(A_{e}-A_{t}\right)-\mathrm{t}$ ) и модели псевдо-второго порядка (зависимость $\mathrm{t} / A_{t}-\mathrm{t}$ ).

Установлено, что сорбция $\mathrm{Cu}^{2+}$ наилучшим образом описывается моделью псевдо-второго порядка. Ультразвуковая кавитационная диспергация торфа приводит к увеличению скорости сорбции по сравнению с необработанным гидратированным образцом. Можно предположить, что в результате ультразвуковой диспергации происходит дробление частиц, увеличение содержания доступных для контакта с $\mathrm{Cu}^{2+}$ групп, несущих избыточный отрицательный заряд, что приводит и к возрастанию сорбции.

Полноту извлечения ионов меди (II) из рассматриваемых реальных объектов в условиях эксперимента оценивали, рассчитывая, как описано выше, параметр $R$, \%, результаты представлены в таблице 4.

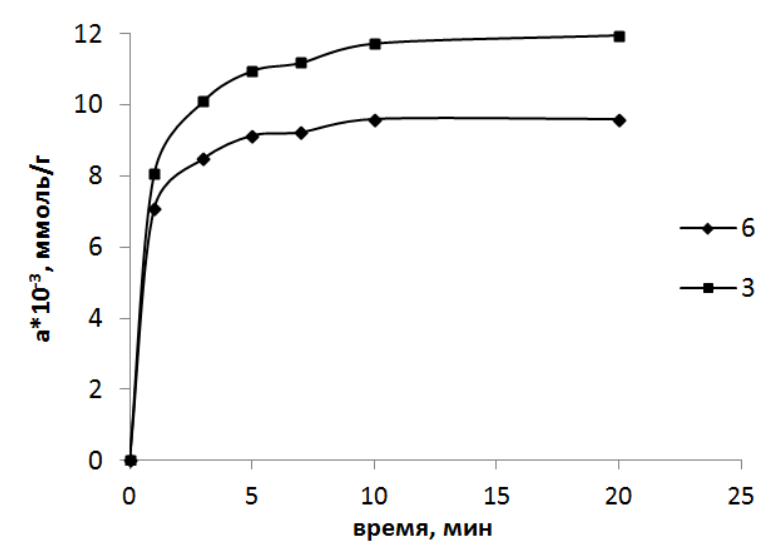

Рис. 4. Кинетические кривые сорбции ионов $\mathrm{Cu}^{2+}$ на образцах 3,6
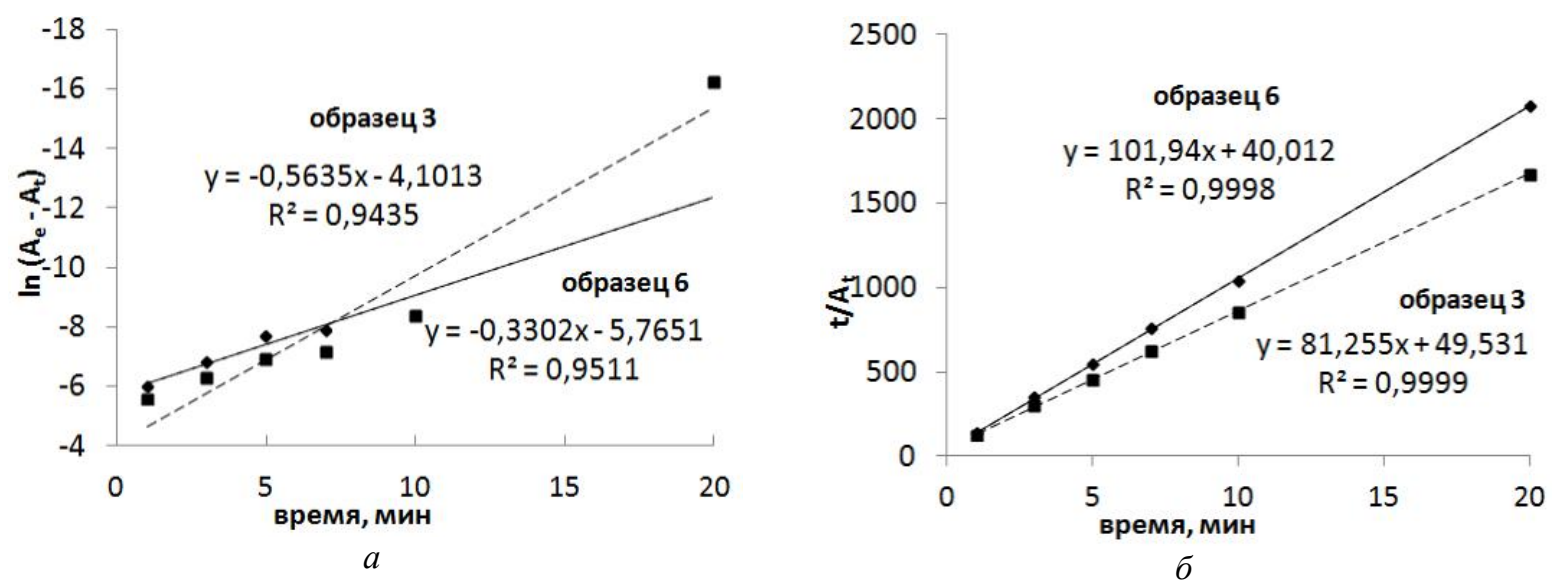

Рис. 5. Анаморфозы кинетических кривых образцов 3 и 6 в моделях псевдо-первого порядка $(a)$ и псевдо-второго порядка (б) 
Таблица 4. Результаты экспериментального изучения сорбции $\mathrm{Cu}^{2+}$ из сточных вод диспергированным торфом при массовом соотношении раствор : сорбент $=1000: 1 ; 500: 1$ и $200: 1$

\begin{tabular}{|c|c|c|c|c|c|c|c|c|c|}
\hline \multirow{3}{*}{$\begin{array}{c}\text { № } \\
\text { образца }\end{array}$} & \multicolumn{9}{|c|}{ Массовое соотношение раствор : сорбент } \\
\hline & \multicolumn{3}{|c|}{$1000: 1$} & \multicolumn{3}{|c|}{$500: 1$} & \multicolumn{3}{|c|}{$200: 1$} \\
\hline & $\begin{array}{c}\mathrm{C}_{\text {равн }}, \\
\mathrm{M} / \text { дм }^{3}\end{array}$ & $\mathrm{~A}, \mathrm{M \Gamma} / \Gamma$ & $\mathrm{R}, \%$ & $\begin{array}{l}\mathrm{C}_{\mathrm{paвH}}, \\
\mathrm{M \Gamma} / \mathrm{дM}^{3}\end{array}$ & $\mathrm{~A}, \mathrm{Mг} / \Gamma$ & $\mathrm{R}, \%$ & $\begin{array}{l}\mathrm{C}_{\text {равн }}, \\
\mathrm{M \Gamma} / \mathrm{ZM}^{3}\end{array}$ & А мг/Г & $\mathrm{R}, \%$ \\
\hline \multicolumn{10}{|c|}{$\mathrm{C}_{0}=0,173 \mathrm{мг} /$ дм $^{3}$} \\
\hline 1 & 0,036 & 0,149 & 79,12 & 0,034 & 0,076 & 80,57 & 0,026 & 0,032 & 85,14 \\
\hline 2 & 0,039 & 0,126 & 77,68 & 0,027 & 0,068 & 84,17 & 0,024 & 0,028 & 86,34 \\
\hline 3 & 0,029 & 0,166 & 83,45 & 0,021 & 0,086 & 87,78 & 0,018 & 0,036 & 89,47 \\
\hline 4 & 0,040 & 0,128 & 76,96 & 0,025 & 0,071 & 85,62 & 0,022 & 0,029 & 87,30 \\
\hline \multicolumn{10}{|c|}{$\mathrm{C}_{0}=0,066 \mathrm{мг} /$ дм $^{3}$} \\
\hline 1 & 0,023 & 0,043 & 65,49 & 0,019 & 0,024 & 71,16 & 0,018 & 0,010 & 72,42 \\
\hline 2 & 0,030 & 0,034 & 54,16 & 0,022 & 0,020 & 66,12 & 0,019 & 0,010 & 71,79 \\
\hline 3 & 0,01 & 0,056 & 84,38 & 0,008 & 0,029 & 88,16 & 0,007 & 0,012 & 88,79 \\
\hline 4 & 0,012 & 0,054 & 81,86 & 0,011 & 0,027 & 83,12 & 0,010 & 0,011 & 84,38 \\
\hline
\end{tabular}

Анализ данных, представленных в таблице 4, показывает, что независимо от концентрации ионов меди (II) в сточной воде наибольшая степень извлечения характерна для образца 3. Для сточной воды, в которой содержание ионов меди (II) составляло 0,173 мг/дм³ ${ }^{3}$ степень извлечения меняется значительно при увеличении массы внесенного торфа с 1 до 2 г/кг и достигает концентраций, допустимых для стока в городскую канализацию. Для сточной воды с низким содержанием $\mathrm{Cu}^{2+}$ внесение 1 г торфа на 1 кг воды снижает остаточную концентрацию до допустимых значений, поэтому расход торфа более 2 г/кг для доочистки стоков можно считать нецелесообразным.

Еще одним параметром эффективности сорбционной доочистки является отношение исходной концентрации $\mathrm{Cu}^{2+}$ к остаточной $\left(\mathrm{C}_{0} / \mathrm{C}_{\text {равн }}\right)$, показывающий, во сколько раз снижается концентрация ионов меди в водных растворах в результате сорбции.

На рисунке 6 представлены диаграммы зависимости указанного параметра от соотношения масс раствор : сорбент. Наибольшее снижение концентрации характерно для торфа со временем обработки 10 мин.

Использование торфа, подвергшегося ультразвуковой кавитационной диспергации, в качестве сорбента для доочистки стоков гальванических производств, позволяет значительно снизить содержание ионов меди (II) в воде и достичь нормативов сброса в городскую канализацию. Появление цветности очищаемой воды является недостатком, ограничивающим применение диспергированного торфа в системе водоочистки предприятий. Предварительное промывание торфа раствором щелочи приводит к снижению цветности, но одновременно с этим снижается и сорбционная емкость торфа по причине вымывания водорастворимых гуминовых кислот [14]. Поиск путей снижения цветности при сохранении сорбционных свойств торфа является перспективным направлением дальнейших исследований.

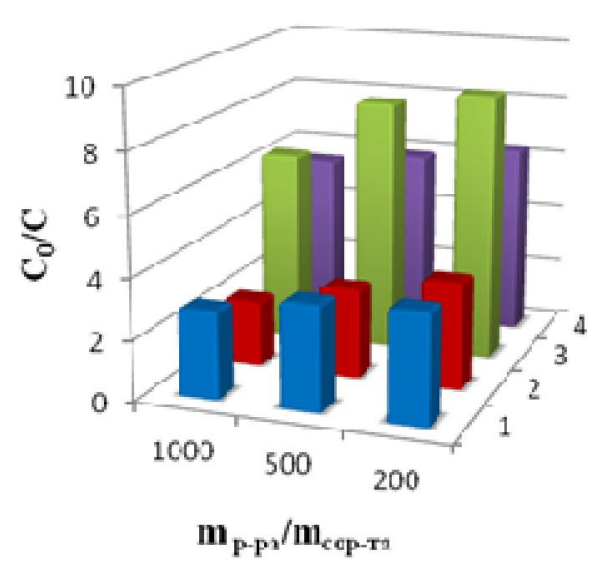

$a$

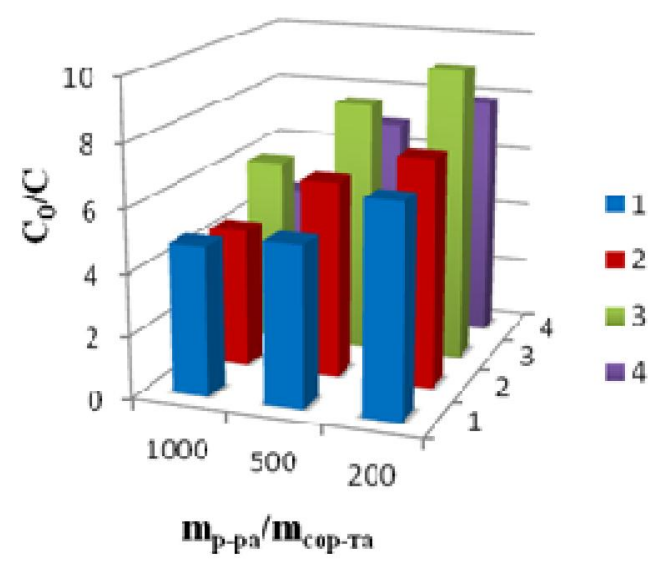

6

Рис. 6. Зависимость кратности извлечения $\mathrm{C}_{0} / \mathrm{C}$ отm $\mathrm{p}_{\mathrm{p} a} / \mathrm{m}_{\text {сор-та }}$ образцами $1-4$ из сточной воды с $\mathrm{C}_{0}=0,066 \mathrm{мг} /$ дм $^{3}$ (а) и $\mathrm{C}_{0}=0,173 \mathrm{мг} /$ дм$^{3}$ (б) 


\section{Bbыводbl}

Метод ультразвуковой кавитационной диспергации торфа до заданных нано-размеров при высоком статическом давлении приводит к увеличению содержания извлекаемых гуминовых кислот и уменьшению количества битумоидов, целлюлозы и лигнина. $\mathrm{COE}$ торфа по отношению к $\mathrm{Cu}^{2+}$ увеличивается в 2,1 раза по сравнению с исходным образцом. Механизм сорбции ионов меди (II) образце торфа преимущественно хемосорбция, основанная на комплексообразовании, на образцах торфа, подвергшегося диспергации механизм сочетанный включает такие составляющие, как комплексообразование, осаждение, ионный обмен, адсорбцию. Сорбционные свойства улучшаются при ультразвуковой кавитационной диспергации торфов до 10 мин. Дальнейшее увеличение продолжительности ультразуковой обработки до 15 мин приводит к снижению сорбционной емкости торфа по отношению к ионам меди (II), вероятно, при этом увеличивается неоднородность сорбционных центров при одновременном снижении их количества за счет процессов агрегации, происходящих между мелкодисперсными частицами торфа.

\section{Список литературь}

1. Лозинская Е.Ф., Митракова Т.Н., Жиляева Н.А. Изучение сорбционных свойств природных сорбентов по отношению к ионам меди (II) // Ученые записки. Электронный научный журнал Курского государственного университета. 2013. №3. [Электронный ресурс]. URL: http://scientific-notes.ru/pdf/032-025.pdf.

2. Смирнов А.Д. Сорбционная очистка воды. Л., 1982. 168 с.

3. Щуклин П.В., Ромахина Е.Ю. Анализ основных направлений очистки производственных сточных вод от ионов тяжелых металлов // Вестник ПГТУ. Урбанистика. 2011. №3. С. 108-119.

4. Наумова Л.Б., Горленко Н.П., Казарин А.И. Обменные катионы и их влияние на гидрофильность торфа // Химия растительного сырья. 2003. №3. С. 51-56.

5. Дементьева Т.В., Богданова О.Ю., Шинкеева Н.А. Физикохимия и биология торфа. Руководство по методам изучения трансформации органического вещества торфов: методическое пособие. Томск, 2011. 68 с.

6. Патент 2533235 (РФ). Способ получения биогеля и биогель / О.В. Володина, А.В. Смородько. 07.08.2014.

7. ПНД Ф 14.1:2.48-96. Количественный химический анализ вод. Методика выполнения измерений массовых концентраций ионов меди в природных и сточных водах фотометрическим методом с диэтилдитиокарбаматом свинца. М., 2004. 11 с.

8. Марков В.Ф., Формазюк Н.И., Маскаева Л.Н., Макурин Ю.Н., Степановских Е.И. Извлечение меди (II) из промывных вод композиционным сорбентом Dowex Marathon C - гидроксид железа // Конденсированные среды и межфазные границы. 2006. Т. 8, №1. С. 29-35.

9. Котов В.В., Ненахов Д.В., Гасанова Е.С., Стекольников К.Е. Состав и кислотно-основные свойства фракций фульвокислот чернозема выщелоченного // Сорбционные и хроматографические процессы. 2010. Т. 10, вып. 1. С. 47-53.

10. Данченко Н.Н. Функциональный состав гумусовых кислот: определение и взаимосвязь с реакционной способностью : дисс. ... канд. хим. наук. М., 1997. 137 с.

11. Джайлс Ч. Адсорбция из растворов на поверхности твердых тел. М., 1986. 488 с.

12. Соколова Т.А., Трофимов С.Я. Сорбционные свойств почв. Адсорбция. Катионный обмен: учебное пособие по некоторым главам химии почв. Тула, 2009. 172 с.

13. Cheung W.H., Ng J.C.Y., McKay G. Kinetic analysis of the sorption of copper (II) ions on chitosan // J. Chem. Techol. Biotechol. 2003. Vol. 78, N5. Pp. 562-571.

14. Варфоломеев А.А., Космачевская Н.П., Синегибская А.Д., Ершов А.А., Русина О.Б., Донская Т.А., Изучение сорбционных свойств верхового торфа Братского района по отношению к d-металлам // Системы. Методы. Технологии. 2010. №6. С. 132-135. 
Lozinskaia E.F. ${ }^{1}$, Kosolapova N.I. ${ }^{l}$, Smorod'ko A.V. ${ }^{2}$, Mitrakova T.N. ${ }^{*}$ OF ULTRASONIC CAVITATION DISPERSION ON FRACTIONAL COMPOSITION AND SORPTION PROPERTIES OF PEAT FOR COPPER (II) IONS

${ }^{1}$ Kursk state university, Radishcheva st., 33, Kursk, 305000 (Russia), e-mail: t-mitrakova@ rambler.ru

${ }^{2}$ LLC «Trade-production company «Kavita»», B. Galushkina st., 23, Moscow, 129301 (Russia),

e-mail:Torf-info@yandex.ru

The ultrasonic cavitation-aided dispersion of peat to the given nano-size at a high static pressure makes it possible to produce a product having valuable consumer properties. In determining the fractional and group composition of the peat's organic substance that underwent dispersion and the original sample by the N.N. Bambalov and T.Ya. Belenkaya method it was shown that the dispersion reduces the bitumoid content by 2,1 times, and that of hardly hydrolysable (cellulose) and nonhydrolysable (lignin) substances by 2,0 and 1,3 times. At the same time, this increases the content of humic acids extracted by $0,1 \mathrm{M}$ alkali solution (by 1,6 times) and by $0,025 \mathrm{M}$ solution of sodium pyrophosphate (by 5,9 times), building up the mass fraction of the total water-soluble and easily hydrolysable substances (by 1,4 times) relative to the original peat.

Also observed is the improvement of sorption capabilities in relation to copper ions (II). For peat samples with a different degree of dispersion the maximum degree of copper ions (II) sorption is reached at pH equal to 4.6 and is maintained practically without changes up to 7,2. The maximum sorption on the original peat takes place in the interval of $\mathrm{pH} 6,2$ to 6,4 . The sorption isotherms are of the L types. As a result of the ultrasonic cavitation-aided treatment the peat sorption capacity increases by 2,1 times. The better sorption capability is possessed by the peat sample which underwent treatment for $10 \mathrm{~min}(\mathrm{COE}=1,65$ $\mathrm{mmol} / \mathrm{g})$.

The study of kinetic dependencies showed that the process of sorption on the studied sorbents proceeds rather fast and practically ends in $7 \mathrm{~min}$. The ultrasonic cavitation-aided dispersion of peat increases the sorption speed constant.

It has been shown that it is possible to use the dispersed peat as a sorbent for after-purification of sewage from copper ions (II) of galvanic productions which had come though the dolomite filter. It has been established that the peat which underwent ultrasonic cavitation-aided treatment for $10 \mathrm{~min}$ is characterized by a higher degree of extraction. The after-sorption copper content is reduced by 9,49 times, the residual concentration being $0,01-0,03 \mathrm{mg} / \mathrm{dm}^{3}$.

Keywords: peat, ultrasonic dispersion, sorption, copper ions, wastewater.

\section{References}

1. Lozinskaia E.F., Mitrakova T.N., Zhiliaeva N.A. Uchenye zapiski. Elektronnyi nauchnyi zhurnal Kurskogo gosudarstvennogo universiteta, 2013, no. 3, URL: http://scientific-notes.ru/pdf/032-025.pdf. (in Russ.).

2. Smirnov A.D. Sorbtsionnaia ochistka vody. [Sorption water treatment]. Leningrad, 1982, 168 p. (in Russ.).

3. Shchuklin P.V., Romakhina E.Iu. Vestnik PGTU. Urbanistika, 2011, no. 3, pp. 108-119. (in Russ.).

4. Naumova L.B., Gorlenko N.P., Kazarin A.I. Khimiia rastitel'nogo syr'ia, 2003, no. 3, pp. 51-56. (in Russ.).

5. Dement'eva T.V., Bogdanova O.Iu., Shinkeeva N.A. Fizikokhimiia i biologiia torfa. Rukovodstvo po metodam izucheniia transformatsii organicheskogo veshchestva torfov: metodicheskoe posobie. [Physical Chemistry and Biology of peat. Manual methods for the study of the transformation of organic matter of peat: Manual]. Tomsk, 2011, 68 p. (in Russ.).

6. $\quad$ Patent 2533235 (RU). 2014. (in Russ.).

7. PND F 14.1:2.48-96. Kolichestvennyi khimicheskii analiz vod. Metodika vypolneniia izmerenii massovykh kontsentratsii ionov medi $v$ prirodnykh $i$ stochnykh vodakh fotometricheskim metodom $s$ dietilditiokarbamatom svintsa. [Federal environmental regulations 14.1: 2.48-96. Quantitative chemical analysis of water. Methods of measurement of mass concentration of copper ions in natural and sewage diethyldithiocarbamate photometric method with lead]. Moscow, 2004, 11 p. (in Russ.).

8. Markov V.F., Formaziuk N.I., Maskaeva L.N., Makurin Iu.N., Stepanovskikh E.I. Kondensirovannye sredy $i$ mezhfaznye granitsy, 2006, vol. 8, no. 1, pp. 29-35. (in Russ.).

9. Kotov V.V., Nenakhov D.V., Gasanova E.S., Stekol'nikov K.E. Sorbtsionnye i khromatograficheskie protsessy, 2010, vol. 10, issue 1, pp. 47-53. (in Russ.).

10. Danchenko N.N. Funktsional'nyi sostav gumusovykh kislot: opredelenie i vzaimosviaz's reaktsionnoi sposobnost'iu : diss. ... kand. khim. nauk. [Functional composition of humic acids: determination and relation to reactivity: the dissertation Candidate of Chemistry]. Moscow, 1997, 137 p. (in Russ.).

11. Dzhails Ch. Adsorbtsiia iz rastvorov na poverkhnosti tverdykh tel. [Adsorption of solutions onto solid surfaces]. Moscow, 1986, 488 p. (in Russ.).

12. Sokolova T.A., Trofimov S.Ia. Sorbtsionnye svoistv pochv. Adsorbtsiia. Kationnyi obmen: uchebnoe posobie po nekotorym glavam khimii pochv. [The sorption properties of soils. Adsorption. Cation exchange: a tutorial on some of the heads of soil chemistry]. Tula, 2009, 172 p. (in Russ.).

13. Cheung W.H., Ng J.C.Y., McKay G. J. Chem. Techol. Biotechol., 2003, vol. 78, no. 5, pp. 562-571.

14. Varfolomeev A.A., Kosmachevskaia N.P., Sinegibskaia A.D., Ershov A.A., Rusina O.B., Donskaia T.A. Sistemy. Metody. Tekhnologii, 2010, no. 6, pp. 132-135. (in Russ.).

Received July 1, 2014

Revised February 4, 2015

\footnotetext{
* Corresponding author.
} 
